\title{
CORRESPONDENCE
}

\section{Science in India}

SIR,-Dr V. H. Shah's suicide, and this is the second occasion that an Indian scientist has committed suicide, has exposed only the tip of an iceberg of the tremendous frustrations bright young scientists experience working in junior positions in some of the universities and research laboratories. The organization of research in India, both in the university and public research laboratories, is, as you have rightly pointed out, "too rigid, too hierarchical" and too authoritarian. Such an organization in any system, whether social, political or scientific, leads to the formation of narrow "yes men" cliques and results in demoralizing and stifling of independent minds. There would have been little progress in sciences and arts for that matter in the world without the presence of questioning minds. The present state of Indian science is not only not conducive to the progress of independent minds but demoralizing and frustrating, which in some cases leads to suicide while in others, if the person is adventurous enough to seek a position abroad, where he can work in a freer environment and have a chance to prove his abilities. This is the major reason, low salary scales, unemployment and under employment being other minor reasons, why large numbers of Indian scientists emigrate.

The Atomic Energy Commission Research Laboratories of India are an exception to this authoritarian organization, and this was due to the capable founder, Dr Homi J. Bhabha, who brought to bear his independent mind on the organization and attracted bright young scientists by way of encouraging an independent and non-authoritarian attitude to scientific research and better salary scales than anywhere else, including the Indian Administration Services (called the Indian Civil Service in the days of the British Raj). The then Prime Minister of India, Jawahar Lal Nehru, respected Bhabha for this and allowed him freedom from a lot of outdated bureaucratic rules still being observed in other institutions. Here is a case of a politician contributing to the progress of Indian science, and no Indian has done more in this field than Nehru. You maintain that a Cabinet Minister should not be the Chairman of the Research Council. The presence of the Minister, or the Prime Minister, actually is a help, for as an outsider he can bring some independence and fair play to the present authoritarian organization. It is the organization of Indian science which is to blame for the present state of affairs and, unless there are radical changes in the outlook of those in the positions of authority, the presence of an independent outsider, such as a Cabinet Minister, or any pub. lic figure, will be necessary. I believe that the junior cadre of the Indian scientists is as good as anywhere in the world; the present organization, however, is so frustrating, and it is herre that the changes are needed so that some of these bright scientists with respect for independence can come forward to lead Indian science and technology.

In the present circumstances, however, it is not easy to bring about a change since those enjoying authority will not like to see a reduction in their authority. The only way to change this is to start a discussion in independent scientific journals, such as Nature, and you have done a great service in initi. ating such a discussion.

Indian scientists, whether in junior or senior positions, face great challenges and can contribute to the betterment of the Indian society. But this can only be done by creating a proper environment for encouraging bright, independent young minds. I very much hope that well intentioned people, both in the Indian government as well as in research institutions and universities, will assert themselves to improve the present organization of the Indian science which leads to such tragedies as Dr Shah's suicide. Yours faithfully, K. C. Tripathi

16 St John's Way, Hempton, Deddington, Oxford

\section{Military Sponsorship}

SIR,--We have recently been circulated with details of a proposed Advanced Study Institute on proteins of the nervous system. Whilst we welcome such a development in principle, we were deeply disturbed to discover that its sponsoring agency was the North Atlan- tic Treaty Organization (NATO). As is well known, NATO is primarily a military organization, and whilst in recent years its activities have ramified in a variety of directions, we must not forget what its primary mission is.

Sponsorship by a military organization of a scientific meeting must raise a number of questions. Are the deliberations of the meeting of use for military purposes? Is free scientific communication a permitted consequence of the meeting? What are the motivations and purposes of the sponsors?

In commenting on these questions, which have the gravest implications for participants in the Institute, we must note the following:

(1) Research on the mode of action of the nervous system at the biochemical level, and particularly on synapses and their related pharmacology, has been funded by military institutions in the USA, UK, West Germany, Australia, Canada and, doubtless, the USSR, on an increasing scale over the past two decades for its potential in the development of chemical weaponry. Weapons systems based on this research, and whose use would be a clear violation of international law, are currently stockpiled by a number of NATO countries, including, particularly, the US, and have indeed reportedly been used by the US in Vietnam.

(2) Frequently the military purposes for which research grants from Defence Departments have been given have not been revealed by the sponsors to participating scientists, who have accepted the grants believing them to have quite other implications. A recent case, at Stanford, has received extensive coverage in Science $(\mathbf{1 7 5}, 866 ; 1972)$.

(3) Free communication at a NATO summer school is rendered improbable because it is highly unlikely that scientists from the Soviet Union, Eastern European Countries, China, Cuba, or the Democratic Republic of Vietnam would be able to attend.

(4) Although we recognize that a "cultural" role is built into the terms of the NATO treaty, it is necessary to consider whether, in such cases as this, the cloak of scientific respectability is being used to lend spurious legitimation to a primarily military organization.

We have written individually to all 
the named participants in the Study Institute, soliciting comments from them on these views, but would welcome the opportunity of opening the debate up within a wider section of scientific opinion, through your columns. Can we invite those readers of Nature who have views on this matter to communicate directly with us?

Yours faithfully,
JIM COHEN
JOHN HAMBLEY
JAVAD HASHTEROUDIAN
JEFF HAYWOOD
LES PEARCE
KEN RICHARDSON
STEVEN ROSE
ARUN SINHA
DAVID SPEARS
BRIAN TIPLADY

Brain Research Group*,

Open University,

Walton,

Bletchley,

Buckinghamshire

*Correspondence to the Group.

\section{Predicting Population}

SIR,-There are two additional factors in the prediction of population besides those which were mentioned in John Maddox's article (Nature, 236, 267 ; 1972), which seem to me to be worth comment.

The first is that in educated and civilized communities, people's behaviour in reproductive as well as other respects is determined not only by their immediate and past environment as it is with most other creatures, but also with their expectations for the future. In consequence, coming events cast their shadow before on birth rates to an extent which is becoming increas. ingly important.

Arising out of this is the second factor which I would like to mention. This is rather like an extension of the uncertainty principle in physics. When Ehrlich, or Forrester and his computers, make convincingly unpleasant predictions concerning world population, these predictions will be read and understood by large numbers of people whose behaviour may thereby be affec- ted. Therefore even if the prophets have taken every possible existing factor into account, they cannot take into account the effects of their own predictions.

It is difficult to feed into a computer analysis the effects of knowledge of its own extrapolations on birth rates or pollution. It is, however, abundantly apparent that our responses to pollution and population changes are far more determined by their rates of change, and hence the direct extrapolations of their effect, than they are by the present magnitudes. Forrester explicitly rules this out in his computer calculations, and thereby, it seems to me, very reliably invalidates them.

This is not a criticism of the value of predictions; rather it is an explanation of where their value lies. A prediction which could not be modified by a change in our actions really would be useless. Yours faithfully,

J. H. FREMLIN

Department of Physics,

University of Birmingham,

PO Box 363,

Birmingham B15 2TT

\section{Obituary}

\section{Professor N. P. Buu-Hoï}

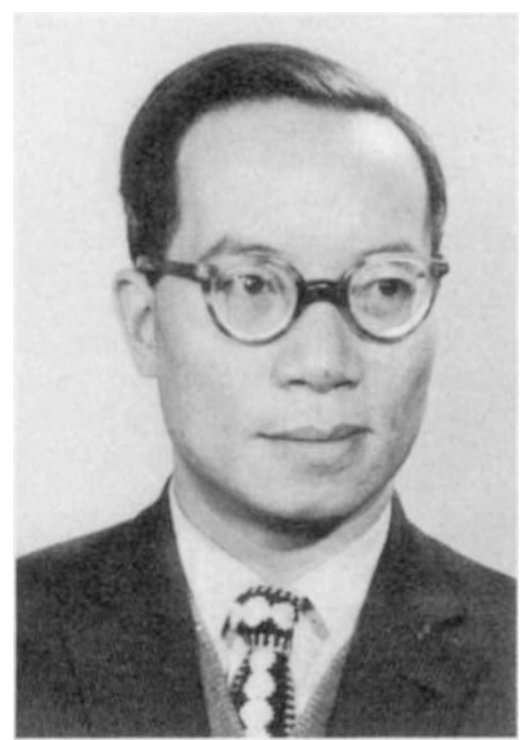

Professor BuU-Hoï, French and Vietnamese expert in medicinal chemistry and cancer research, died of a heart attack in Paris on January 28, 1972.

N. P. Buu-Hoï was born on June 15 , 1915 , in Hué, and is of the Royal Family of Vietnam. Partly because of the desire of his parents and partly because of his own belief in the human value of science, he did not follow the traditional political career of his family, but instead took up research in biochemistry and medicine. He studied pharmacology at the University of Hanoi, and upon arrival in France in 1935 took degrees in physics and chemistry at the University of Paris. During the Second World War he volunteered as a pharmacist in the medical service of the French Army. From 1941 he held appointments on the research staff of the Centre National de la Recherche Scientifique (CNRS) where in 1960 he became director of research.

After 1941, he worked at the Institute of Chemical Physics under the late Professor Jean Perrin, then studied spectroscopy applied to organic chemistry, under the late Professor Ramart-Lucas at the Sorbonne. From 1945 to 1947 he was assistant professor at the Ecole Polytechnique, and then went to the Radium Institute of the University of Paris as director of the Department of Organic and Medicinal Chemistry, where for more than twenty years he was the closest collaborator of the renowned cancerologist Professor Antoine Lacassagne, who himself died recently (see Nature, 235, $291 ;$ 1972). In 1960 he transferred his laboratories to a laboratory group at Gif-sur-Yvette, where he led a team of some 20 researchers while continuing his collaboration with Professor Lacassagne at the Radium Institute. From 1967, he also directed a second team of researchers at the CNRS Laboratories in Orleans.

The main research interests of BuuHoi were in the fields of biochemistry and pharmacolugy, but his exceptional gift as an organic chemist enabled him to apply the whole panorama of possibilities of synthetic chemistry to the search for new compounds of biochemical, biological, and pharmacological activity.

His scientific bibliography comprises over 1,000 papers and chapters in books, and records fundamental knowledge in chemistry, pharmacology and cancer research. From his laboratory stem drugs now in clinical practice as well as in experimental development, such as new thiourea derivatives for tuberculosis and leprosy, thyronamine for cardiac conditions, 6-aminochrysene for splenomegaly and cancer chemotherapy, and anti-rheumatismal agents and analgesics.

The study of chemical carcinogenesis represents the core of his scientific acti- 